\title{
Nondestructive Evaluation of Ceramic Matrix Composite Combustor Components
}

\author{
J. G. Sun, ${ }^{1}$ M. J. Verrilli, ${ }^{2}$ R. Stephan, ${ }^{3}$ T. R. Barnett, ${ }^{4}$ and G. Ojard ${ }^{5}$ \\ ${ }^{1}$ Argonne National Laboratory, Argonne, IL \\ ${ }^{2}$ NASA Glenn Research Center, Cleveland, OH \\ ${ }^{3}$ Pratt \& Whitney, East Hardford, CT 06108 \\ ${ }^{4}$ Southern Research Institute, Birmingham, AL \\ ${ }^{5}$ United Technologies Research Center, East Hardford, CT
}

July 2002

\begin{abstract}
The submitted manuscript has been created by the
University of Chicago as Operator of Argonne

National Laboratory (ÒArgonné) under Contract No

W-31-109-ENG-38 with the U.S. Department of

Energy. The U.S. Government retains for itself, and

others acting on its behalf, a paid-up, nonexclusive,

irrevocable worldwide license in said article to

reproduce, prepare derivative works, distribute copies

to the public, and perform publicly and display

publicly, by or on behalf of the Government.
\end{abstract}

Presented at $29^{\text {th }}$ Annual Review of Progress in Quantitative Nondestructive Evaluation, Bellingham, WA, July 14-19, 2002.

Work sponsored by the U.S. Department of Energy under Contract W-31-109-ENG-38. 


\title{
Nondestructive Evaluation of Ceramic Matrix Composite Combustor Components
}

\author{
J. G. Sun ${ }^{1}$, M. J. Verrilli ${ }^{2}$, R. Stephan ${ }^{3}$, T. R. Barnett ${ }^{4}$ and G. Ojard ${ }^{5}$ \\ ${ }^{1}$ Argonne National Laboratory, Argonne, IL 60439 \\ ${ }^{2}$ NASA Glenn Research Center, Cleveland, OH 44135 \\ ${ }^{3}$ Pratt \& Whitney, East Hartford, CT 06108 \\ ${ }^{4}$ Southern Research Institute, Birmingham, AL 35211 \\ ${ }^{5}$ United Technologies Research Center, East Hartford, CT 06108
}

\begin{abstract}
Combustor liners fabricated from a $\mathrm{SiC} / \mathrm{SiC}$ composite were nondestructively interrogated before and after combustion rig testing. The combustor liners were inspected by X-ray, ultrasonic and thermographic techniques. In addition, mechanical test results were obtained from witness coupons, representing the as-manufactured liners, and from coupons machined from the components after combustion exposure. Thermography indications were found to correlate with reduced material properties obtained after rig testing. Microstructural examination of the $\mathrm{SiC} / \mathrm{SiC}$ liners revealed the thermography indications to be delaminations and damaged fiber tows.
\end{abstract}

\section{INTRODUCTION}

The pursuit of lower emissions and higher performance from gas turbine engines requires the development of innovative concepts, such as use of advanced materials for key engine components. One key engine component is the combustor, where liners fabricated from a ceramic matrix composite, silicon carbide fibers in a silicon carbide matrix $(\mathrm{SiC} / \mathrm{SiC})$, are under evaluation. $\mathrm{SiC} / \mathrm{SiC}$ composite technology has progressed from fabrication of simple coupons to subelements and now to actual components [1-4]. This last area posed a significant challenge to nondestructive evaluation (NDE) techniques due to the complex geometries involved.

To evaluate $\mathrm{SiC} / \mathrm{SiC}$ components in a combustion environment, the Rich-burn, Quick-quench, Lean-burn (RQL) sector rig was designed and fabricated. The purpose of the sector rig testing was to demonstrate the structural durability of the SiC/SiC liners in a combustion environment where stresses, temperatures, and pressures would as accurately as possible reflect the operating conditions found in a turbine engine.

$\mathrm{X}$-ray, ultrasonic and thermographic techniques were used to inspect the asmanufactured $\mathrm{SiC} / \mathrm{SiC}$ components and the liners after combustion testing. The purpose of this study was to characterize the post-exposure condition of one $\mathrm{SiC} / \mathrm{SiC}$ combustor liner part through NDE evaluation via thermography and mechanical property measurement.

\section{EXPERIMENTAL}

\section{Material and Component}

Combustor liners were manufactured by Honeywell Advanced Composites from a $\mathrm{SiC} / \mathrm{SiC}$ composite developed under the NASA Enabling Propulsion Materials program. 
A chemical vapor infiltrated, slurry-cast, and melt-infiltrated $\mathrm{SiC}$ matrix was reinforced with Sylramic SiC fibers. The fiber tows were woven into 5-harness satin weave cloth. More details on the $\mathrm{SiC} / \mathrm{SiC}$ material can be found in reference 5 .

The sector rig liner set consisted of 6 different component geometries and a total of 28 liners (Fig 1). For this study, one of the six components, the lean zone inner diameter liner (LZID) was examined. The LZIDs are curved plates, each covering about a $30^{\circ}$ arc of the total $60^{\circ}$ sector, as shown in Fig.1. A twelve ply thick leading edge reinforces the attachment hole region. The rest of the LZID is six plies thick. LZIDs containing 34 and $40 \%$ fiber volume were tested.

Flexure coupons were machined from the as-manufactured and exposed sector parts to obtain mechanical properties. The as-manufactured parts were supplied with extra material that was machined into test coupons. The exposed parts were machined to obtain test coupons of the same geometry as was used for the witness testing. All testing was conducted at $815{ }^{\circ} \mathrm{C}$. More details on the mechanical test procedures can be found in reference 6 .

\section{Combustion Testing}

The Preheated Combustor and Materials Test Facility (PCMTF) at NASA Glenn Research Center was used to conduct the RQL sector rig testing. Air temperature (T3), pressure (P3), and flow rate (W3) were varied to approximate the anticipated service cycle of the High Speed Civil Transport (HSCT) engine combustor [7]. All aspects of an HSCT flight operation, such as take-off, climb, cruise, and decent, are included in the 230 minute test cycle.

The combustion testing was periodically interrupted in order to remove some of the $\mathrm{SiC} / \mathrm{SiC}$ liners for post-exposure analysis. After completion of 260 hours of operation, the rig was disassembled and all $\mathrm{SiC} / \mathrm{SiC}$ combustor liners were removed.

\section{NDE Techniques}

As-manufactured and combustion-exposed $\mathrm{SiC} / \mathrm{SiC}$ components were inspected using x-ray film radiography, ultrasonic, and thermography. Radiography is sensitive to volumetric features such as large voids and gross porosity or thickness variations, but cannot detect planar (laminar) features such as delaminations in ceramic matrix composites. Ultrasonic techniques have high sensitive on detection of delaminations, but quantitative interpretation of the data is difficult as they are affected by many experimental setup parameters. Thermography techniques are also very sensitive to delaminations, and when used in a through-transmission setup to determine thermal

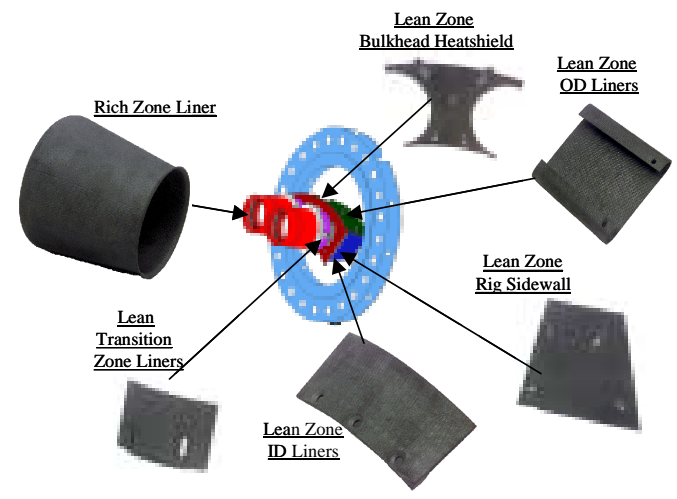

Figure 1 - Schematic of RQL sector rig and images of all the $\mathrm{SiC} / \mathrm{SiC}$ parts. 
diffusivity, which is a material property, the data can be quantitatively analyzed to relate with the detailed structures of defects [8]. In this study, only the thermography results will be discussed.

A transient through-transmission thermography method was used on the tested liners. Two high-energy flash lamps generate a heat pulse that travels through the thickness of the parts (Fig. 2). The raw data consists of multiple layered images acquired at $120 \mathrm{~Hz}$. A total of 40 frames were typically suitable to capture the temperature rise. The analysis technique was based on that given by Parker [8]. The front surface temperature rise is given by

$$
T(L, t)=\frac{Q}{\rho C L}\left[1+2 \sum_{n=1}^{\infty}(-1)^{n} \exp \left(-\frac{n^{2} \pi^{2}}{L^{2}} \alpha t\right)\right]
$$

where $\mathrm{L}$ is the liner thickness, $\alpha$ is the thermal diffusivity, $\mathrm{t}$ is time elapsed, $\rho$ is the material density, $Q$ is the amount of heat absorbed by the liner from the flash lamps, and $C$ is the specific heat of the material. Using the time to reach half of the maximum detected temperature $\left(t_{1 / 2}\right)$, the thermal diffusivity at each pixel can be calculated using:

$$
\alpha=\frac{1.37 L^{2}}{\pi^{2} t_{1 / 2}}
$$

At regions of planar defects, such as delaminations, the material surface temperature is lower than that of the undamaged composite and it will take a longer $t_{1 / 2}$ to reach the equilibrium part temperature (note that the part will eventually reach an equilibrium constant temperature if sufficient time is given). Therefore, from the above Eq. 2, the regions with damaged material will have lower thermal diffusivities.

The thermal diffusivity calculated from Eq. 2 is proportional to the thickness squared. Because it is impossible to provide thickness values for all pixels of an imaged part, it is common to use a representative thickness (typically the averaged thickness) for calculation of the diffusivity image for the entire part. This method has some shortcomings when thickness variation is large. For example, in the case of a uniform material of constant diffusivity, Eq. 2 dictates that for a pixel with a thickness twice that of a second pixel, the half-rise-time $t_{1 / 2}$ at the first pixel will be 4 times longer than that of the second. However, if we choose to use the thickness of the second pixel for calculating diffusivities at all pixels, the calculated diffusivity at the first pixel would appear to be 4 times lower than its real diffusivity. Similarly, the diffusivity calculated

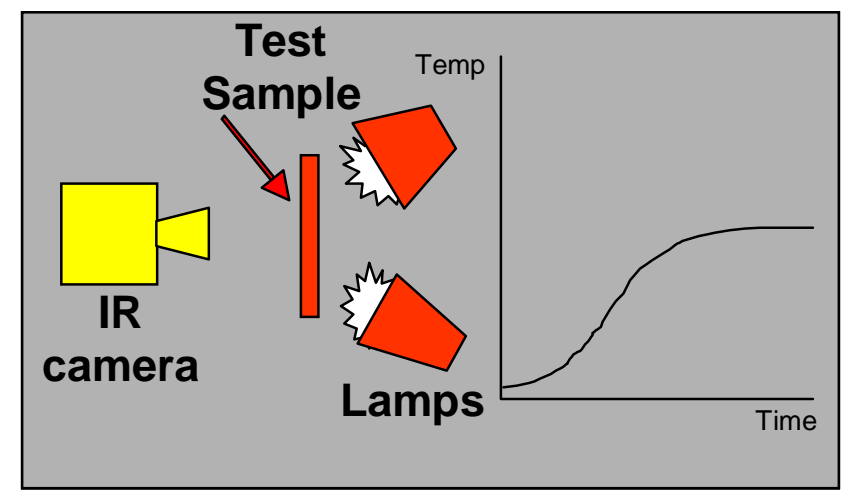

Figure 2 - Schematic of the through-transmission thermography test configuration. 
from Eq. 2 appears to be higher for a thinner pixel. Therefore, care should be taken when interpreting measured diffusivity images. Note that this equation is exact when a test part has a uniform thickness.

\section{RESULTS}

An example of thermography results obtained for three LZIDs after 115 hours of sector rig testing is shown in Figure 3. Part 216-1 contains $34 \%$ fiber volume fraction, and the other two contain $40 \%$. Thickness of the middle sections of the liners was used to calculate the diffusivity values in the image. The apparent diffusivities are lower at the strips with fastener holes where the material is thicker and higher at the left edges where material is thinner. In addition to these diffusivity variations due to thickness change, regions with considerably lower diffusivities can be observed in all liners, especially for 216-1.

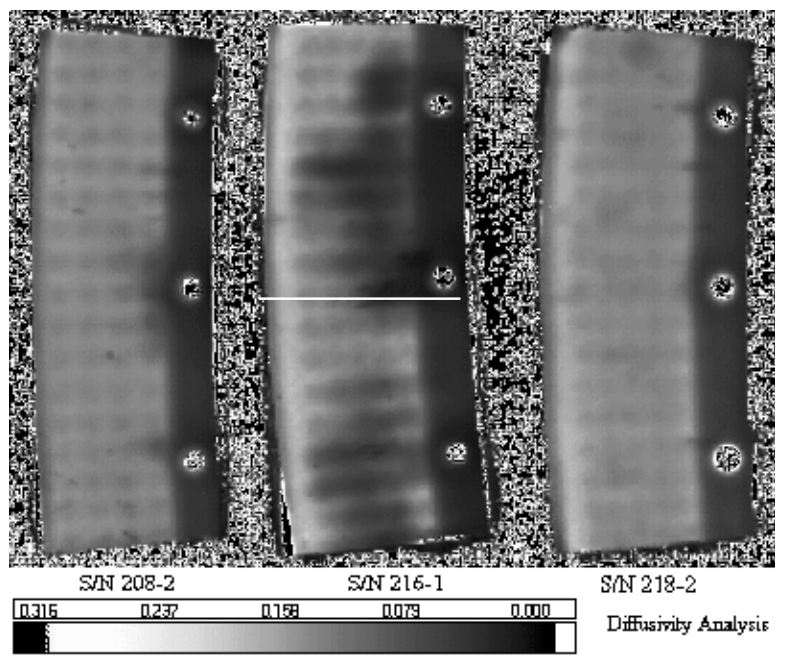

Figure 3 - Thermography of three SiC/SiC liners after 115 hours of sector rig testing. Part 216-1 contains 34 $\%$ fibers, and the other two contain $40 \%$ fibers.

To investigate the origin of local lower diffusivity values, a LZID was sectioned and polished. Figure 4 shows the microstructure of a cross-section taken from 216-1. The line on the thermography image in Fig. 3 shows the location of the cross-section. Damaged $\mathrm{SiC}$ fiber tows and delaminations cracks can be seen. The diffusivity reduction shown in Fig. 3 is related to the damage (i.e., delamination) of the CMC material due to the sector testing. For a single delamination, Sun [8] showed that the diffusivity reduction could be used to determine the (air gap) thickness of the delamination.

Thermal diffusivity data for another LZID with $34 \%$ fiber volume, which was exposed in the combustion environment for 145 hours, is shown in Fig. 5. Thermal diffusivity values are plotted in Fig. 5a along 7 horizontal lines passing through several interesting regions in the thermal diffusivity image of 216-2. Although there is thickness variation near both vertical edges of the liner, the thickness is uniform in the middle section and is used in the diffusivity calculation. In this middle section, the measured diffusivity is found uniform in undamaged regions (e.g., line 7). Reduced diffusivity representing damage of varying severity is shown in other regions (lines 1-6). Figure 5b plots the width-averaged diffusivity along the length for the regions where 4 coupons were machined from the part to obtain flexure strength. It is apparent that coupons 2-4 contained large damaged areas with significant thermal diffusivity reductions and coupon 1 had only slight damage near 


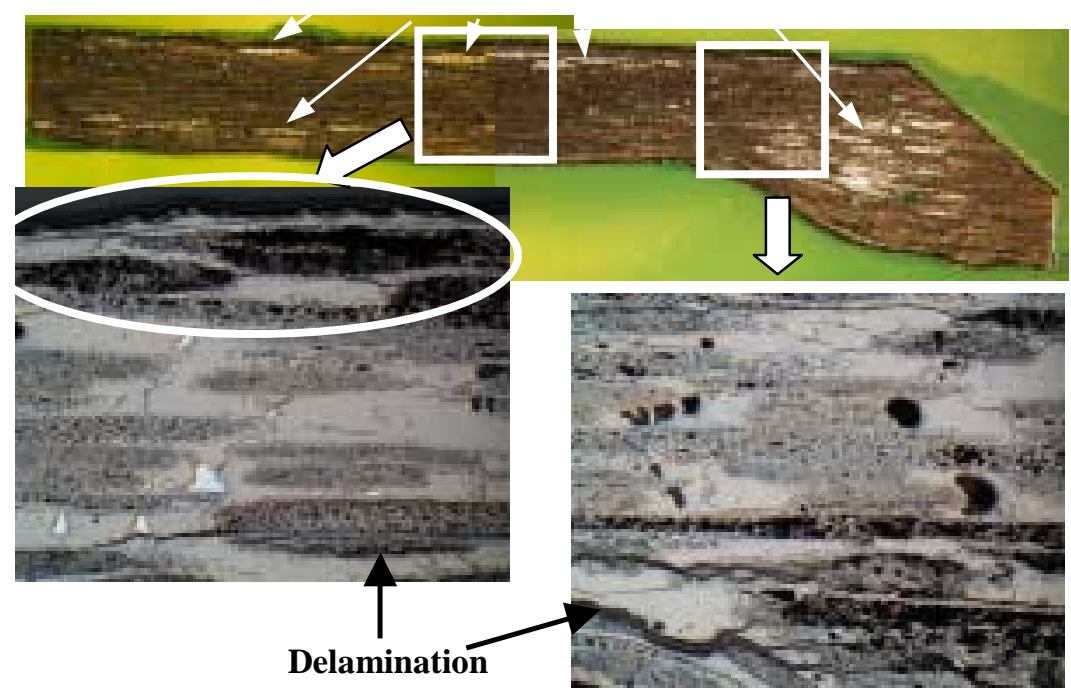

Figure 4 - Microstructure of LZID 216-1 after 115 hours of combustion exposure. The line in Fig. 3 shows the location of this section. Arrows indicate damaged tows.
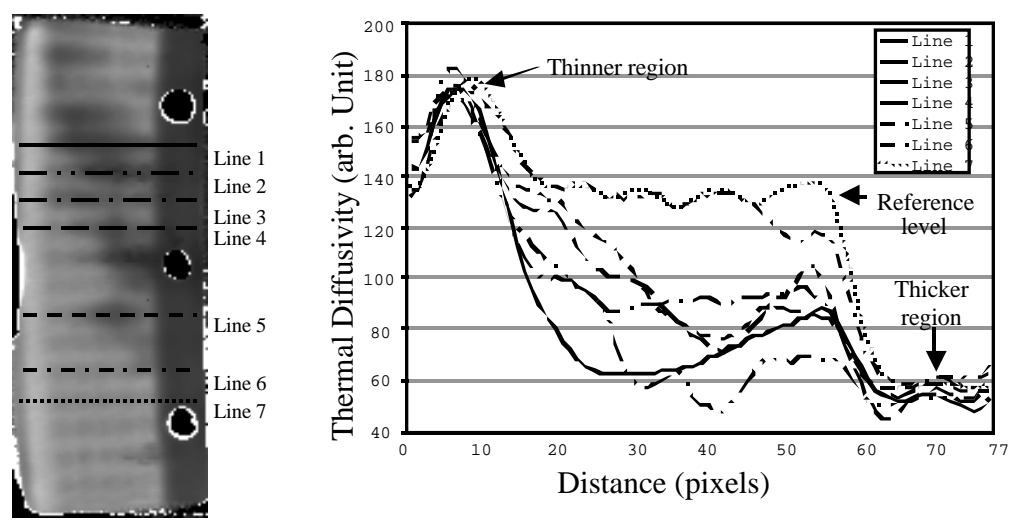

a)
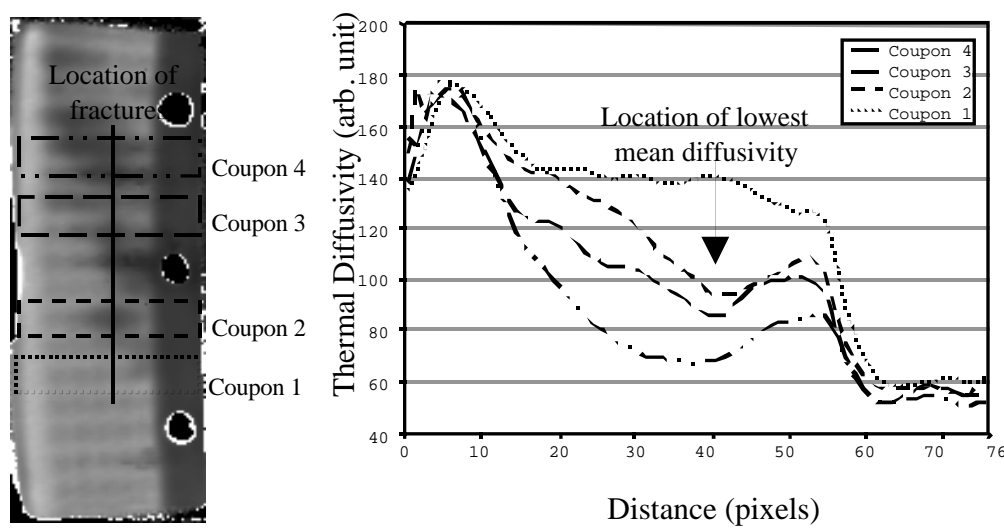

b)

Figure 5 - Thermal diffusivity data for LZID 216-2 after $145 \mathrm{hrs}$ of combustion exposure, a) line plots at 7 part locations, b) average values for regions of coupons machined for strength measurement. 
the region of thickness transition at right. It is interesting to note that fracture occurred near the locations where lowest diffusivities were observed for coupons 2-4.

Flexure strengths obtained from these coupons is compared to the thermal diffusivity

Table I: Comparison of thermal diffusivity and coupon strength for

LZID 216-2 after 145 hours of testing in combustion environment.

\begin{tabular}{|c|c|c|}
\hline $\begin{array}{c}\text { Coupon } \\
\text { ID }\end{array}$ & $\begin{array}{c}\alpha / \alpha_{m} \\
\text { (in region of coupon failure) }\end{array}$ & $\begin{array}{c}815^{\circ} \mathrm{C} \text { Post-test flex } \\
\text { strength, MPa }\end{array}$ \\
\hline 1 & 1 & 262 \\
\hline 2 & 0.6 & 229 \\
\hline 3 & 0.56 & 207 \\
\hline 4 & 0.47 & 131 \\
\hline
\end{tabular}

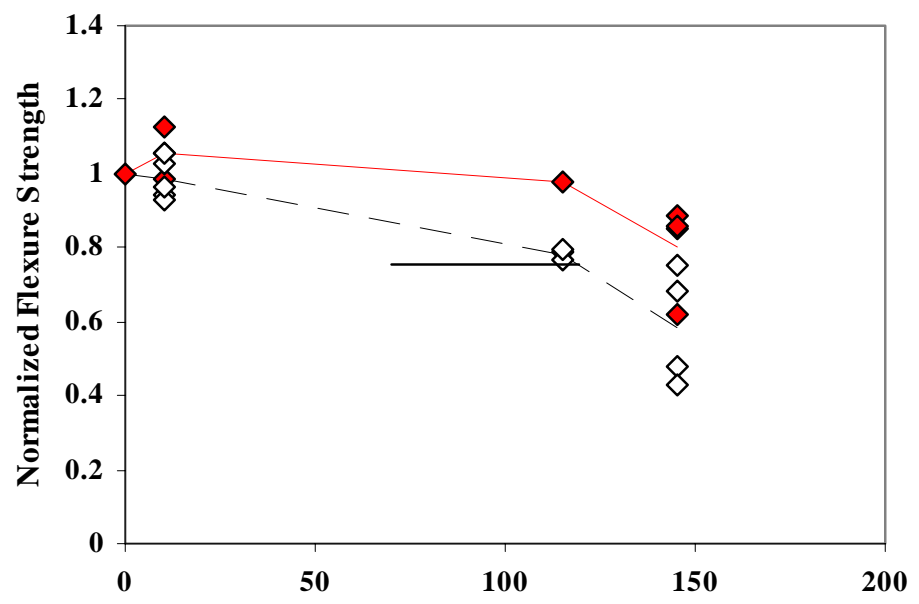

Exposure Time in Combustion Environment, hours

a)

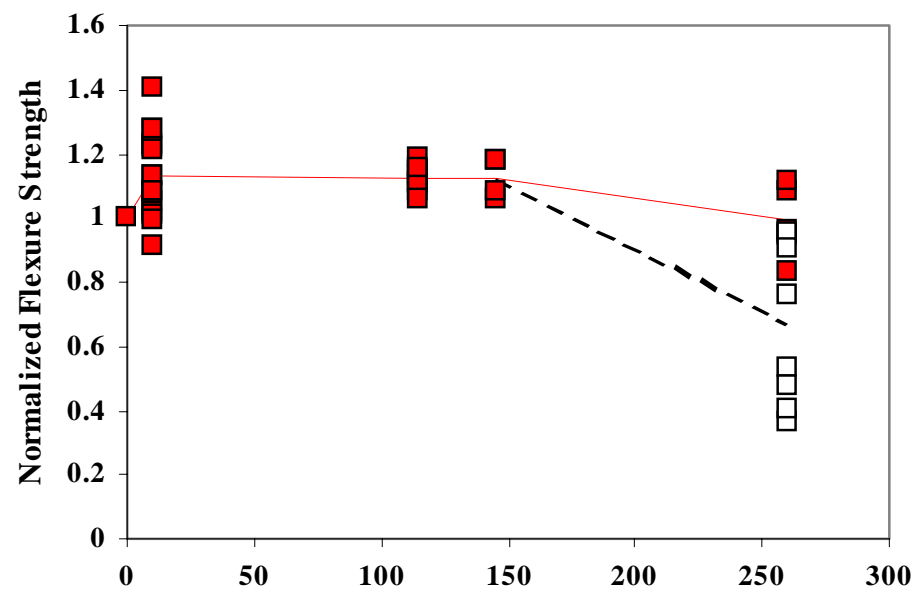

Exposure Time in Combustion Environment, hours

b)

Figure 6 - Normalized flexure strength data obtained at $815{ }^{\circ} \mathrm{C}$ as a function of exposure time for coupons machined from LZIDs, a) data for coupons from $34 \%$ fiber volume parts, b) data for coupons from $40 \%$ fiber volume parts. 
in Table I. The post-exposure strength obtained from these coupons decreased with decreasing ratio of the coupon-averaged thermal diffusivity to the mean thermal diffusivity $\left(\alpha / \alpha_{m}\right)$, revealing the correlation between the thermal diffusivity data and strength.

The normalized flexure strength versus combustion exposure time for coupons machined from all LZIDs tested in the sector rig is shown in Figure 6. The normalized flexure strength was calculated as the ratio of the strength of a coupon machined from a tested LZID to the average as-fabricated strength obtained from the LZID witness coupons for the same part. Strength decreases with increasing exposure time for the parts with 34 $\%$ fiber volume, while the strength of the $40 \%$ fiber volume decreased after 115 hours of exposure. Also, coupons machined from component regions with thermography indications had lower strengths than coupons from regions of no NDE indications. The strength data sets for coupons with and without NDE indications follow the same trends as a function of exposure time.

\section{SUMMARY}

1. Combustor liners, fabricated from $\mathrm{SiC} / \mathrm{SiC}$, were tested in an aircraft engine environment using the RQL sector rig for up to 260 hours. SiC/SiC liners were periodically removed during the rig operation to conduct post-exposure analysis.

2. Degradation of the $\mathrm{SiC} / \mathrm{SiC}$ material occurred and was in the form of delaminations and damage fiber tows for the combustor liner parts examined in this study, namely the lean zone inner diameter liners (LZID).

3. Thermography was effective in imaging this damage in the $\mathrm{SiC} / \mathrm{SiC}$ liners, whereas radiography and ultrasonic inspections were less sensitive.

4. Strength was measured by testing coupons machined from combustion-exposed parts and compared to witness (as-manufactured) data. For parts with $40 \%$ fiber volume, strength decreased after $115 \mathrm{hrs}$. However, exposure of only 10 hours decreased the strength of parts with $34 \%$ fiber volume.

5. For the exposed parts, coupons machined from regions that had thermography indications had lower strengths than coupons machined from regions of no indications.

6. Local thermal diffusivity correlated with measured coupon strength for exposed $\mathrm{SiC} / \mathrm{SiC}$ combustor liners.

\section{ACKNOWLEDGEMENTS}

This work was supported by the U.S. Department of Energy under contract W-31-109-ENG-38.

\section{REFERENCES}

1. Brewer, D., Ojard, G., and Gibler, M., "Ceramic Matrix Composite Combustor Liner Rig Test", prepared for Expo 2000: ASME Turbo Expo, Land, Sea \& Air, May 8-11, 2000, Munich, Germany, ASME paper TE00CER03-03, May, 2000.

2. Miriyala, N., Fahme, A., and van Roode, M., "Ceramic Stationary Gas Turbine Program - Combustor Liner Development Summary", prepared for Turbo Expo 2001: ASME Turbo Expo, Land, Sea \& Air, June 4-7, 2001, New Orleans, LA., ASME paper 2001-GT-0512. 
3. Corman, G., Dean, A., et. al, "Rig and Gas Turbine Testing of MI-CMC Combustor and Shroud Components", prepared for Turbo Expo 2001: ASME Turbo Expo, Land, Sea \& Air, June 4-7, 2001, New Orleans, LA., ASME paper 2001-GT-0593

4. Igashira, K.-I., Matsubara, G., Matsuda, Y., and Imamura, A., "Development of the Advanced Combustor Liner Composed of CMC/GMC Hybrid Composite Material", prepared for Turbo Expo 2001: ASME Turbo Expo, Land, Sea \& Air, June 4-7, 2001, New Orleans, LA., ASME paper 2001-GT-0511.

5. Brewer, D.,'HSR/EPM Combustion Materials Development Program”, Materials Science and Engineering, A261, pp. 284-291, 1999.

6. Verrilli, M.J., Ojard, G., Barnett, T. R., Sun, J.G., and Baaklini, G., "Evaluation of Post-Exposure Properties of SiC/SiC Combustor Liners Tested in the RQL Sector Rig”, to appear in the proceedings of the $26^{\text {th }}$ Annual International Conference on Advanced Ceramics and Composites, held in Cocoa Beach, FL, Jan. 13-18, 2002.

7. Shaw, R. J., Koops, L., and Hines, R.," Progress Toward Meeting the Propulsion Technology Challenges for a $21^{\text {st }}$ Century High-Speed Civil Transport", NASA Technical Memorandum 113161, ISABE-97-7045, prepared for the XIII International Symposium on Air Breathing Engines, sponsored by AIAA, Chattanooga, TN, Sept. 1997.

8. Sun, J. G., "Analysis of Quantitative Measurement of Defects by Pulsed Thermal Imaging," in Review of Progress in QNDE, Vol. 21, pp. 572-576, eds. D. O. Thompson and D. E. Chimenti, 2002.

9. Parker, W. J., Jenkins, R. J., Butler, C. P., and Abbott, G. L., "Flash Method of Determining Thermal Diffusivity, Heat Capacity, and Thermal Conductivity," J. Appl. Phys., Vol. 32, pp. 1679-1684, 1961. 